Research Article

\title{
Framework of the Smart Finance and Accounting Management Model under the Artificial Intelligence Perspective
}

\author{
Yaping Chen \\ College of Management, Shaanxi Institute of International Trade \& Commerce, Xi'an 712046, Shaanxi, China \\ Correspondence should be addressed to Yaping Chen; 2003020101@st.btbu.edu.cn
}

Received 14 July 2021; Revised 14 August 2021; Accepted 24 August 2021; Published 11 October 2021

Academic Editor: Sang-Bing Tsai

Copyright $\odot 2021$ Yaping Chen. This is an open access article distributed under the Creative Commons Attribution License, which permits unrestricted use, distribution, and reproduction in any medium, provided the original work is properly cited.

\begin{abstract}
With the establishment of modern enterprise systems and the emergence of some large-scale enterprise groups formed through asset reorganization, industry alliances, and cross-industry mergers, new requirements have been put forward for the financial management mode of enterprise groups. This article mainly studies the development of the smart accounting management model architecture under the artificial intelligence perspective. On the accounting sharing service platform, the accounting sharing center does not belong to the logistics branch of any region. Through the accounting sharing center, it provides unified and standardized accounting, asset management, currency revenue and expenditure, etc., for the branches of the logistics company. At the same time, in the network environment, the financial and accounting sharing platform is not unilaterally closed. As each branch under unified management, it has the power to feedback, suggest, and supervise the financial and accounting sharing platform. When testing, one only needs to focus on the external properties of the program, without considering the internal logical structure and internal characteristics of the program at all. The system under test is regarded as a sealed black box, and the boundary value analysis method, the equivalence class division method, and causality are used. Technical methods such as the graph method and error speculation method are tested at the system interface to detect whether the function of each test can receive and output the results correctly. The implementation of the accounting management model of accounting shared services must ensure that the evaluation results of related work are objective and accurate. It is necessary to ensure that the evaluation index system has a high degree of quantification. In the specific scoring, the full score system can be used to score points by experts to ensure the objectivity of the evaluation results and accuracy while improving the operability and enforceability of the evaluation work. The average value of the operating net profit margin is 0.088731 , and the median value is 0.082263 . The results show that artificial intelligence technology has greatly promoted the development of the smart accounting management model architecture.
\end{abstract}

\section{Introduction}

With the rapid development of modern information technology, the close integration of traditional accounting management and computer technology has effectively promoted the rapid development of accounting management systems in the direction of informatization, networking, and automation. In the process of business development of enterprise groups, how to continuously innovate and reform the group accounting management model in the Internet age to continuously solve the problems that arise in the business development process of enterprise groups, reduce operating risks and accounting risks, and improve market competitiveness in our company group personnel, especially accounting personnel, face a major issue.

In order to optimize the company's current financial and accounting operating system structure and information level, reduce the inefficient repetitive work of the business department, reduce the cost of corporate accounting business processing, and provide better services to internal and external customers of the company. The establishment of a shared accounting service center requires companies to adopt more efficient accounting sharing strategies, strengthen communication with other business departments, and carefully evaluate the basis for handling different accounting services. The financial and accounting sharing 
model requires centralized resources to achieve centralized management and control.

Due to the convenience of the information system, grassroots accounting personnel can log in to the cloud system anytime and anywhere to view and change the enterprise's accounting data, which brings potential information leakage and malicious changes to the risk. The overall goal of Wafula $\mathrm{F}$ is to examine the impact of the accounting structure on the accounting performance of the Kenya Petroleum Sales Company. Specific targets include the impact of debt and equity on the performance of the Kenya Petroleum Sales Company. He uses a descriptive research design. The object of his research is all 35 oil sales companies in Kenya. Use the data collection form for data collection. He edits, organizes, encodes, and classifies the data. When analyzing the data, he used quantitative analysis methods characterized by inference and descriptive statistics, and then explained, and then used graphs and related inferences, frequencies, and percentages to describe and summarize the relevant results. Although his research has certain reference value, there is a lack of discussion on the research results [1]. Gong Q studied the relative importance of banks and stock markets at different stages of economic development. Different from previous studies, he proposed a demand-side theory on the appropriate financial structure of an economy. He found that for developing countries, a bank-based financial structure is more appropriate than a market-based financial structure; for developed countries, a market-based financial structure is more appropriate than a bank-based financial structure. Although his research provides a new perspective for understanding the structural changes of a country's financial system, it lacks necessary data [2]. Chakrabarti D believes that the Reserve Bank of India's recent move to restore the targeted credit distribution policy during the period dominated by neoliberal philosophy requires reconsideration of the role of the policyoriented credit distribution process on financial development and corporate financial structure. His theoretical structure is empirically verified using aggregated and disaggregated (enterprise level) data, including a group of 932 Indian manufacturing companies. Although his research can be used as an effective tool to guide financial development, it is not very accurate [3]. Ansca CC aims to determine the impact of capital structure on the performance of Indonesian companies, especially in the precrisis period. After the 2008 financial crisis, the global financial crisis provides an opportunity to examine the impact of the crisis on capital structure and corporate performance. The indicators used for capital structure are the ratio of total liabilities to total assets, the ratio of short-term liabilities to total assets, and the ratio of long-term liabilities to total assets. In addition, company performance is measured by accounting performance (return on assets and return on equity) and market performance (price-earnings ratio and Tobin's Q). The sample he used includes all companies listed on the Indonesian Stock Exchange (IDX) between 2004 and 2017, excluding financial sector companies. His research assumes that capital structure usually has a negative impact on company performance. The global financial crisis (GFC) that occurred in 2008 had a greater negative impact on corporate performance than before and after the crisis. Although his research is relatively comprehensive, the research content lacks certain reference value [4]. Santos $G$ believes that in the current rapid technological progress, it is possible to spread solutions designed to fill gaps in the market and promote profound changes in the traditional financial structure. This finding can be explained by the perceptible movements of different subjects interested in exploring the application of blockchain technology in recent years. Taking into account this change and expected situation, he aims to analyze the views of financial market entities on the possibility of blockchain technology affecting the creation of FI solutions. He conducted this by interviewing 12 managers of institutions operating in a financial environment. Although his research is more accurate, it lacks innovation [5]. Perc M believes that artificial intelligence is being seamlessly integrated into our daily lives, enhancing our knowledge and ability in driving, avoiding traffic, finding friends, choosing the perfect movie, and even cooking healthier meals. It also has a significant impact on many aspects of society and industry, from scientific discovery, health care, and medical diagnosis to smart cities, transportation, and sustainability. He is here to review the social dilemma where personal interests are inconsistent with the interests of others and the special difficulties that artificial intelligence may encounter in making correct decisions. He also reviewed legal challenges, focusing on infringements at least partly or ostensibly caused by artificial intelligence that caused the claimant to suffer loss or injury. Finally, he proposed a vision and a short set of guidelines to constructively alleviate the challenges described [6].

The application of artificial intelligence is specifically integrated into the hospital's financial management, such as financial analysis and financial budgeting. Through the use of artificial intelligence technology, it can help the accounting department to establish a more effective system. This paper introduces the management concept of business process reorganization and designs a comprehensive cost management plan. It not only optimizes accounting activities but also ensures the integration and sharing of enterprise business and accounting information, providing effective guidance for the standardized development of the overall business process of the enterprise, and aims to enrich enterprise management ideas and improve enterprise operating efficiency. Under the background of financial artificial intelligence, this paper studies the construction of accountants' career management system and puts forward suggestions on improving accountants' career planning scheme in Chinese enterprises, which is helpful to cultivate accountants suitable for enterprise development.

\section{Smart Finance and Accounting Management Model Architecture}

2.1. Artificial Intelligence. In order to achieve the purpose of fast and effective accounting, we divide the intelligent accounting information management system into accounting operating system and accounting query system. The research of artificial intelligence is highly technical and professional. Each branch is deep and unconnected, covering a wide range. The research contents of artificial intelligence mainly include knowledge representation and automatic reasoning, search 
method and knowledge processing, machine learning and knowledge acquisition, computer vision and natural language understanding, automatic programming and intelligent robot, etc. Even if they are far away from the company, they can also query real-time accounting information through the website in a timely manner, and the cost of publishing accounting information is very low. Future implementation becomes possible. The emergence of an intelligent accounting management system means that accounting management is efficient and convenient, fully integrated with network technology, and shows mature aspects. Anytime, anywhere, you can see the financial system of a shared system at a glance. The above convenient and rapid system generation is realized by incorporating enterprise ERP accounting information into the system [7].

The HL test divides the data into 10 groups of the same scale according to the predicted probability value and does not consider the number of covariate types and arranges the observed data in ascending order according to their predicted probability. The statistical formula is as follows [8]:

$$
\mathrm{HL}=\sum_{j=1}^{J}\left(\frac{y_{j}-n_{j} \widehat{p}_{j}}{n_{j} \widehat{p}_{j}\left(1-\widehat{p}_{j}\right)}\right) \text {. }
$$

Among them, $J$ is the number of groups, and $J \leq 10 ; n_{j}$ is the number of cases in the $j$-th group; $y_{j}$ is the number of observations of the $j$-th group of events; and $\widehat{p}_{j}$ is the predicted event probability of the $j$-th group [9].

The empirical risk $\operatorname{Remp}(w)$ and the actual risk $R(w)$ satisfy the following relationship with a probability of at least $1-\eta$ :

$$
R(w) \leq R e m p(w)+\sqrt{\frac{h(\ln (2 n / h)+1)-\ln (\eta / 4)}{n}},
$$

where $h$ is the VC dimension of the function set, and $n$ is the number of samples [10].

The classic radial basis function uses the following decision rules:

$$
f(x)=\operatorname{sgn}\left[\sum_{i=1}^{l} a_{i} k_{y}\left(\left|x-x_{i}\right|\right)+b\right] .
$$

Among them, $k_{\gamma}\left(\left|x-x_{i}\right|\right)$ depends on the distance between the two vectors $\left(\left|x-x_{i}\right|\right)[11]$.

In general, a neuron is a nonlinear device with multiple inputs and single outputs, and its expression is as follows:

$$
\left\{\begin{array}{l}
\tau \frac{d u_{i}}{d_{t}}=-u_{i} t+\sum w i_{j} x_{j}(t)-\theta_{i} \\
y_{i} t=f\left[u_{i} t\right]
\end{array} .\right.
$$

Among them, $u_{i}$ is the internal state of the neuron, $\theta_{i}$ is the threshold, and $w i_{j}$ represents the weight connected to the neuron $i_{j}[12]$.

The neuron model can simulate the law of the biological neural network changing with time, and it is usually expressed by the first-order differential equation. The output of the neuron is represented by the function $f$, and the $\mathrm{S}$ function is most commonly used to realize the nonlinear characteristics of the network [13].

$$
f\left(u_{i}\right)=\frac{1}{1+\exp \left(-u_{i} / c\right)^{2}} .
$$

Among them, $c$ is a constant.

The calculation formula for the silhouette indicator of sample $t$ is as follows:

$$
\operatorname{Sil}(t)=\frac{[b(t)-a(t)]}{\max \{a(t), b(t)\}} .
$$

In the formula, $a(t)$ is the average dissimilarity or distance between the sample point $t$ in cluster $\mathrm{C}$ and all other samples in the cluster [14].

The local density $\rho$ is an important variable in the density peak algorithm, and the local density of data points can be defined as

$$
\rho_{i}=\sum_{j} \chi \times\left(d_{i j}-d_{c}\right)
$$

where $d_{i j}$ represents the distance between any two sample points $i$ and $j$ in the data space, and the formula is as follows [15]:

$$
d_{i j}=\operatorname{distance}\left(x_{i}, x_{j}\right) \text {. }
$$

This paper comprehensively considers the distance attributes between data points and the relationship between the density attributes of any data point, and calculates the density attributes and distance attributes through a weighted method, and derives a new similarity calculation method, and then updates the similarity matrix. The new similarity calculation formula is as follows [16]:

$$
S=\frac{\operatorname{Sum}(D(i, j) * \operatorname{rho}(i) * \operatorname{rho}(j))}{\operatorname{Sum}\left(D(i,:)<d_{c}\right)-1} .
$$

In the formula, $D(i, j)$ is the Euclidean distance between data point $i$ and data point $j$, and $\operatorname{rho}(i)$ and $\operatorname{rho}(j)$ represent the local density of data point $i$ and data point $j$, respectively [17].

In the original algorithm, the final clustering center is determined by the data points through the transmission and communication of information, that is, the degree of belonging and attractiveness. However, in the original algorithm, for any data point in the data space, it is actually necessary to consider the influence of the neighboring data point on that point. That is to say, the similarity of data is not only measured by the simple Euclidean distance between two points [18]. follows:

The calculation formula for the degree of attribution is as

$$
\begin{aligned}
& a(i, k)=\min \left\{0, r(k, k)+\sum_{i^{\prime}, s t i^{\prime} \notin\{i, k\}} \max \left\{0, r\left(i^{\prime}, k\right)\right\}\right\}, \\
& a(k, k)=\sum_{i^{\prime}, s t i^{\prime} \neq k} \max \left\{0, r\left(i^{\prime}, k\right)\right\} .
\end{aligned}
$$


In the formula, the value of $a(i, k)$ is the degree of support of $k$ points for its own class representative plus the degree of positive support of other sample points for $k$ as its class representative [19].

In the image, the weighted average value of the pixel value is used to remove the Gaussian noise to obtain the smoothed image $I$ and then obtain the gradient magnitude and direction of each pixel of the image $I$ through first-order differentiation. Among them, the first derivatives in the $x$ and $y$ directions at the pixel point $(i, j)[20]$ are as follows:

$$
\begin{aligned}
& G_{x}(i, j)=\frac{1}{2}(I(i, j+1)-I(i, j)+I(i+1, j+1)-I(i+1, j)), \\
& G_{y}(i, j)=\frac{1}{2}(I(i, j)-I(i+1, j)+I(i, j+1)-I(i+1, j+1)) .
\end{aligned}
$$

Through $G_{x}(i, j)$ and $G_{y}(i, j)$, the gradient amplitude $G(i, j)$ and the gradient direction $\theta(i, j)$ can be obtained:

$$
\begin{aligned}
& G(i, j)=\sqrt{G_{x}^{2}(i, j)+G_{y}^{2}(i, j)}, \\
& \theta(i, j)=\operatorname{arc}\left(\frac{G_{x}(i, j)}{G_{y}(i, j)}\right) .
\end{aligned}
$$

After obtaining the gradient amplitude $G(i, j)$ and the gradient direction $\theta(i, j)$, perform nonmaximum suppression and interpolate the pixel value $(i, j)$ neighborhood in the image along $\theta(i, j)$. When the point $G(i, j)$ is greater than the interpolation point, the pixel value $(i, j)$ is taken as the candidate edge point. Finally, the candidate edge points are selected through the double threshold method to obtain the image edge [21].

\subsection{Smart Finance and Accounting Management Model.} Finance and accounting management plays a major role in corporate management, providing timely, accurate, and complete accounting information and operating conditions to external stakeholders, internally raising funds, investing and using them, providing decision-making support for management, and taking risks. Management and many other tasks related to the healthy and sustainable development of enterprises. With the advent of the knowledge economy and the information age, enterprise competition needs to rely on more internal and external support to make rapid and accurate decisions [22]. The future development of the enterprise puts forward high requirements on the accounting work and has given more and more important management responsibilities. For example, accounting organizations are required to manage information as an important asset and become decisionmaking partners with deep business insights and forwardlooking consultants to allocate and use scarce resources and research methods and measures to reduce costs and maintain a balance of payments. Through the preparation of detailed and accounting plans, it facilitates the value-added financial management of enterprises and improves the efficiency of financial management [23].
In the reconstruction of the enterprise's accounting management model, the basic ability of accounting management is the basis of the model change, and in the basic ability, accounting is the basis of an enterprise's accounting management work, including account setting, voucher control, account book setting, the smooth flow of internal accounting information, etc. In addition to internal control, enterprises also need a relatively complete financial and accounting decision support system in their financial management activities [24]. In the process of supporting financial, professional accounting personnel are required to calculate and track the various accounting activities and accounting indicators of the enterprise in real time. This involves the financial management personnel. The sample companies involved in this article have the problem of uneven quality of financial staff. Therefore, in the process of restructuring the financial management model, companies should pay attention to improving the professionalism of financial management personnel and distinguish between financial management personnel and accounting personnel and establish a professional financial management team to provide for the company's financial management activities [25].

In the SaaS mode, the system needs to provide services for multiple different users and ensure that each user does not affect each other, so virtual host technology is used to build the system architecture. The system structure is shown in Figure 1. It can be seen from the figure that several servers are provided on the SaaS side to provide services for users. Tomcat is installed on each server, and multiple virtual hosts can be created in each Tomcat. Each enterprise's accounting management computer can directly communicate with a virtual host [26]. All virtual hosts will access the back-end database. A schema will be created separately for each company in the database, and each company will access its own schema. Usually 3-4 will be created on one server. This is because considering the limited computing power of a single server, not all virtual hosts are deployed on one server. Of course, if the resources of the database server are limited, you can also install MySQL on multiple servers and then put the schema of each enterprise in different MySQL [27, 28].

\section{System Experiment of the Accounting Management Model}

3.1. Experimental Environment. The network platform serves as the basis for information transmission and sharing. Based on the current situation, with the continuous development of the Internet, the environment for information exchange and resource sharing is also more optimized. With the increase in database capacity, data will be stored uniformly, and the client will simply place some programs corresponding to the browser. Based on the low-cost network, the browser can be used to spread data and promote the development of local area network to wide area network. Based on the dimensions of large enterprises and group companies, no matter where the members are located, when economic business is generated, business and accounting personnel can directly push messages on the client side, 


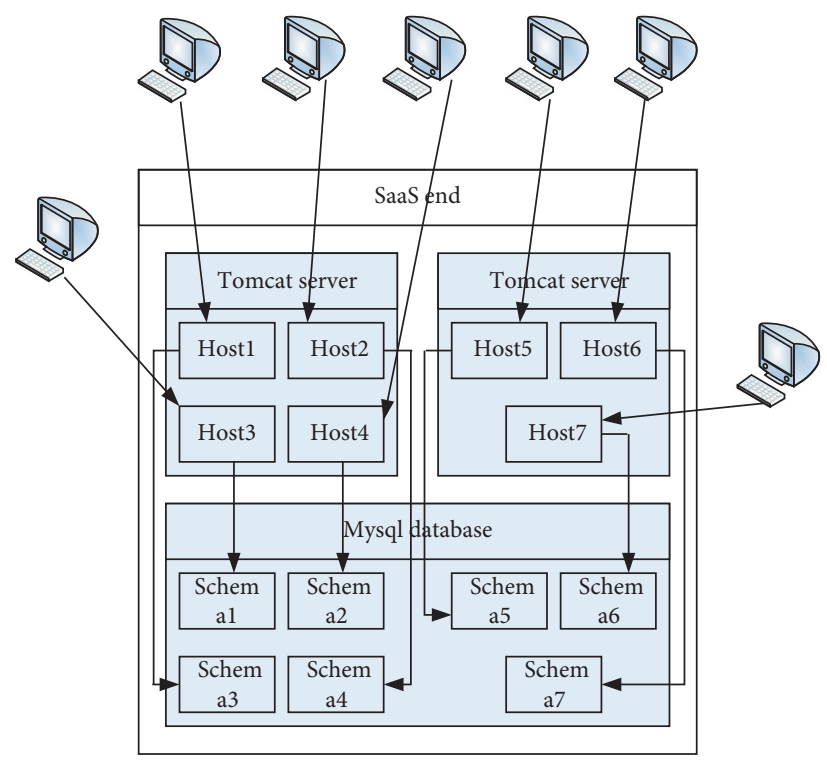

Figure 1: System architecture.

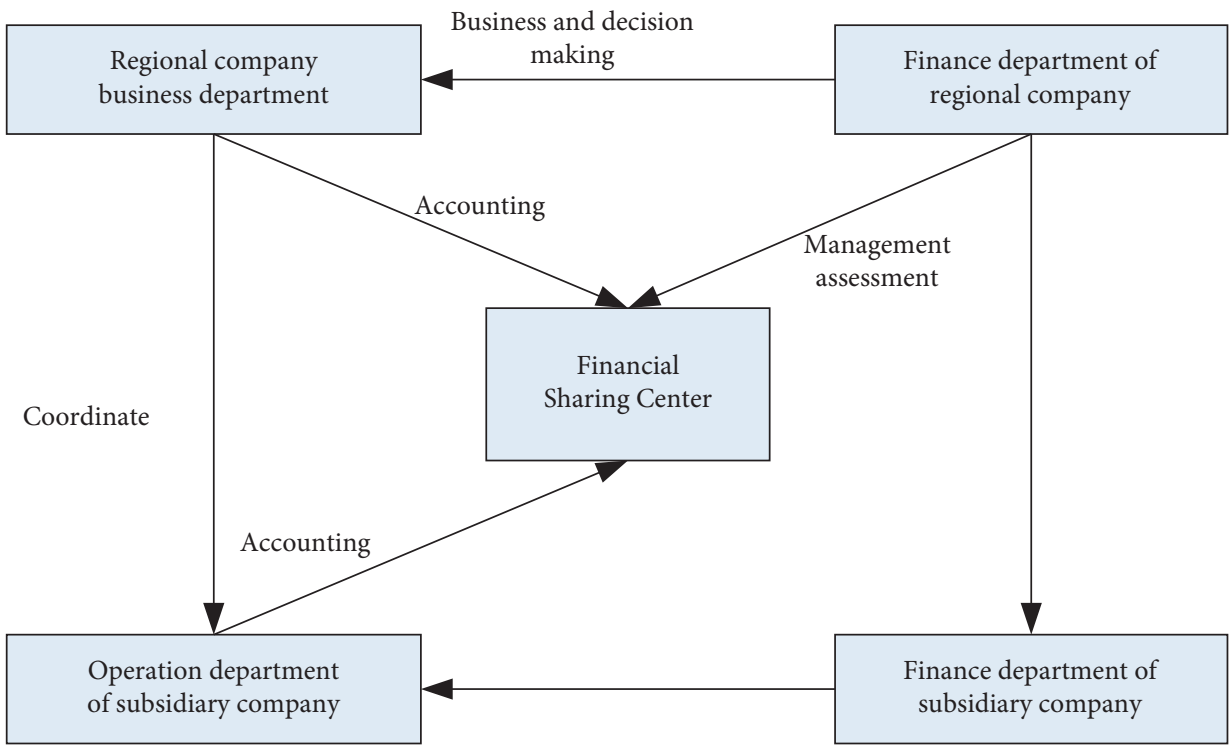

FIgURE 2: Accounting sharing management model.

thereby promoting the improvement of data sharing. The minimum requirements for the software and hardware configuration of the server and client of this system are as follows:

(1) Minimum requirements for server configuration: server operating system: Windows Server 2008; server hardware configuration: CPUP42.8G, hard disk 200G, memory above 4G; development language: Visual Basic; database server: Microsoft SQL Server 2005

(2) Minimum requirements for client configuration: client operating system: Windows XP; client hardware configuration: CPUP41.8G or above, memory above $512 \mathrm{M}$
3.2. Accounting Sharing. On the accounting sharing service platform, the accounting sharing center does not belong to the logistics branch of any region. Through the accounting sharing center, it provides unified and standardized accounting, asset management, currency revenue and expenditure, etc., for the branches of the logistics company, as shown in Figure 2. At the same time, in the network environment, the financial and accounting sharing platform is not unilaterally closed. As each branch under unified management, it has the power to feedback, suggest, and supervise the financial and accounting sharing platform. Streamline the original part of the department's personnel, promote the core competent accounting personnel to serve the corporate development strategy, and provide strategic advice and support for the development of each branch. By 
clarifying the process of each link and the docking of each link, understand which links can use electronic payment, QR code, and other technologies, review the overall link and repeat the link before the platform is built. At the same time, the design of time and business process can divide the functions that need to be retained and the functions that need to be separated in the financial and accounting departments of each branch, to enable the company to do a good job in the reorganization and deployment of man power and timely deployment of resources to the accounting department, and to ensure that the overall operation of the company can remain stable in the future.

3.3. System Test. When testing the system, find out and improve the places that do not meet the needs of users, further improve the actual working ability of the system, correct the test problems existing in the system in time, and debug the system repeatedly until the system is relatively stable. Through the source code of the program, test the code's problems in the path, algorithm, condition, overflow, etc., so as to achieve the purpose that each internal operation conforms to the design specification. The programmer has a clearer understanding of the internal structure of the code and tests the software from the internal logical structure of the code. When testing, you only need to focus on the external properties of the program, without considering the internal logical structure and internal characteristics of the program at all. The system under test is regarded as a sealed black box, and the boundary value analysis method, the equivalence class division method, and causality are used. Technical methods such as graph method and error speculation method are tested at the system interface to detect whether the function of each test can receive and output the results correctly.

\subsection{Effect Evaluation of the Accounting Management Model.} The implementation effects of the financial and accounting management model of the financial and accounting shared services can be divided into two types: direct effects and indirect effects. Through the effect analysis, we can find out the problems in the implementation of the company's financial and accounting shared service management model. Evaluation indicators can be divided into primary and secondary indicators, as shown in Table 1 . The implementation of the accounting management model of accounting shared services must ensure that the evaluation results of related work are objective and accurate. In the specific scoring, the full score system can be used to score points by experts to ensure the objectivity of the evaluation results and accuracy.

\section{Results and Discussion}

The change trend of the weighted task deadline guarantee rate is shown in Figure 3. It can be clearly seen from the figure that the deadline guarantee rate of EDF (earliest deadline first) and HVF (highest value first) decreases sharply as the load increases, and although the performance of IDV decreases as the load increases, the rate of decrease compared with the EDF and HVF algorithms is very slow. Therefore, as the number of tenants continues to increase, the IDV algorithm is more effective in solving the problem of cloud platform resource load balancing than the EDF and HVF algorithms.

The test data results of different numbers of virtual users concurrently logging in to the system are shown in Figure 4. From the perspective of the average response time, the number of concurrent users of the system is optimal within 400 , and the average value is within $30 \mathrm{~s}$, which meets the maximum time limit in the system requirements specification. Some enterprises stipulate that the chief financial officer shall supervise the enterprise, not participate in the daily operation and management of the enterprise, and not act as the financial director of the enterprise. In other enterprises, the CFO has the right of supervision and decisionmaking on major financial matters.

The performance test results are shown in Table 2. Since most of the data operations of this system are executed on the database server in the form of database stored procedures, the CPU usage and memory usage of the corresponding database server are relatively high. According to the access permissions corresponding to the user attributes of different levels, the user's access to different functional modules is restricted. The system interface seen is different. By controlling role access to effectively avoid the possibility of external personnel entering the system, this guarantees another aspect of the security of the system.

This paper selects some indicator data such as solvency, operating ability, profitability, and growth ability and analyzes them with the Pearson correlation coefficient. The results are shown in Table 3. In general, the Pearson correlation coefficient is less than 0.3 as low-degree correlation, between 0.3 and 0.7 is medium correlation, and greater than 0.7 is high correlation. From the data in the table, it can be seen that solvency and operating ability are highly positively correlated with the company's situation; profitability, growth ability, and nonfinancial and accounting indicators are moderately correlated with the company's situation; financial and accounting leverage indicators have a low correlation with the company's situation. However, no matter the degree of correlation is high or low, the data indicators have correlation and collinearity with the company's situation. In order to reduce the collinearity and establish a model, this paper uses the factor molecular method.

Table 4 shows the distribution percentage of accountancy personnel's career replanning and development. Descriptive statistical analysis of the data, the conclusion is that under the background of artificial intelligence, $88.84 \%$ of the investigators have an understanding of artificial intelligence in finance and accounting. Those who do not understand accounted for $11.16 \%$; those who had job crisis awareness accounted for $70.59 \%$, and those who had not yet had crisis awareness accounted for $29.41 \%$; those who had undergone career replanning accounted for $35.50 \%$, and those who were undergoing career replanning accounted for 29.419. Those who do career replanning accounted for $21.91 \%$, and those 
TABLE 1: Effectiveness evaluation criteria.

\begin{tabular}{|c|c|c|}
\hline & First-level evaluation index & Secondary evaluation index \\
\hline \multirow{7}{*}{ Evaluation index } & \multirow{5}{*}{ Direct effect } & Return on net assets \\
\hline & & Asset-liability ratio \\
\hline & & Turnover of total assets \\
\hline & & Growth rate of total assets \\
\hline & & Net profit growth rate \\
\hline & \multirow[b]{2}{*}{ Indirect effect } & $\begin{array}{l}\text { Support for the development of the company } \\
\text { S }\end{array}$ \\
\hline & & $\begin{array}{l}\text { Support for the improvement of the quality of the company's employees } \\
\text { Support for the construction of corporate culture }\end{array}$ \\
\hline
\end{tabular}

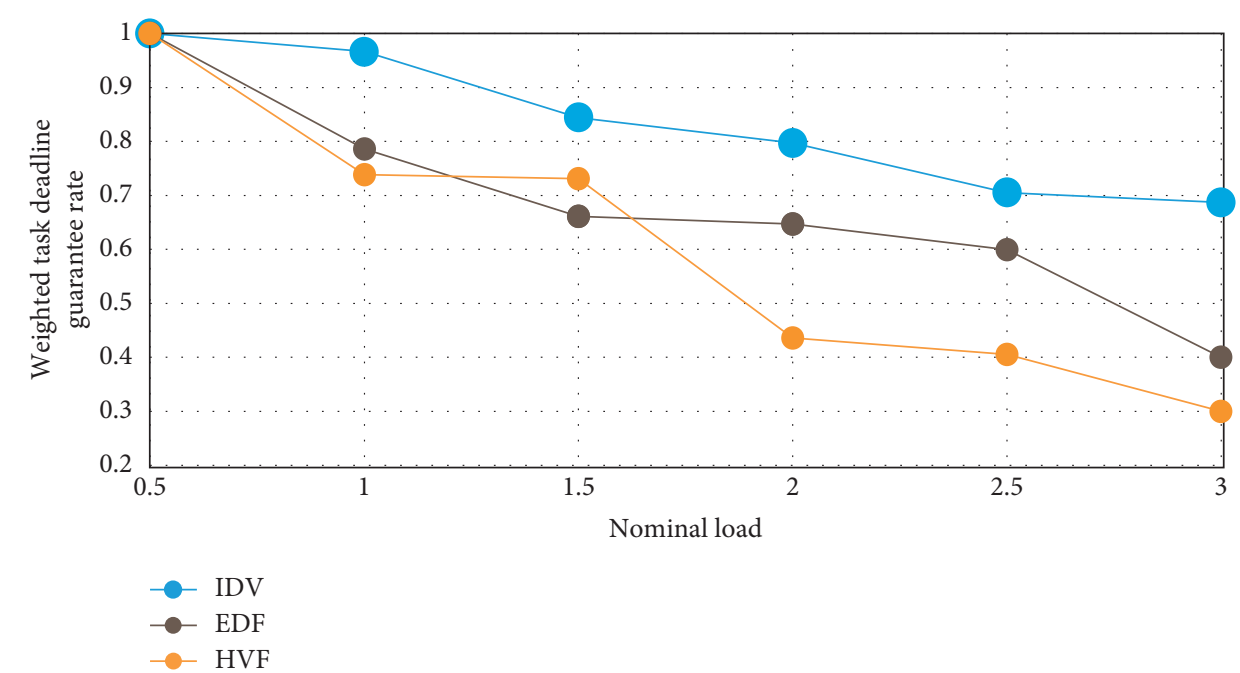

FIGURE 3: Changes in weighted task deadline guarantee rate.

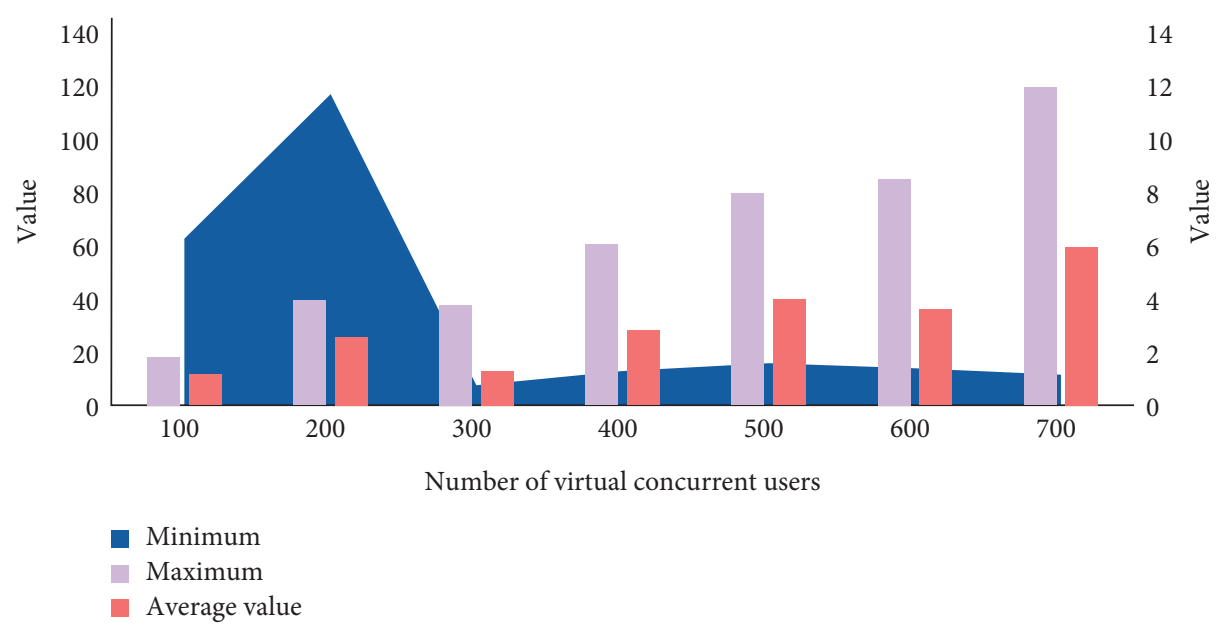

FIgURE 4: Test data results of different numbers of virtual users concurrently logging in to the system.

who did not want to do career replanning accounted for $13.18 \%$. From the survey data, $35.09 \%$ of people have not made career planning or do not want to make career planning at all. $64.91 \%$ of people have already carried out career planning or are in the process of career planning.

Figure 5 shows the statistics of the competence of management accountants. According to the analysis of survey data, more than $68 \%$ of the accounting staff do not have the quality and ability of a management accountant, only $4.6 \%$ are fully qualified as a management accountant, and $17.2 \%$ are generally qualified as a management accountant. Through statistical analysis of data, it is concluded that under the background of artificial intelligence, most accountants do not have the ability to transform management accountants, and accountants need to continuously strengthen the learning of management accountant skills and improve their professional competence. 
Table 2: Performance test results.

\begin{tabular}{|c|c|c|c|}
\hline Test content & Test index & Test result & Expected results \\
\hline \multirow{5}{*}{ Response time } & Average query response time & 1.2 seconds & $<1.5$ seconds \\
\hline & Query maximum response time & 2.3 seconds & $<2.5$ seconds \\
\hline & Average response time for processing applications & 1.8 seconds & $<3$ seconds \\
\hline & Maximum response time for processing applications & 3.2 seconds & $<4$ seconds \\
\hline & Average time of application submission & 1.7 seconds & $<5$ seconds \\
\hline \multirow{2}{*}{ CPU utilization } & Maximum CPU utilization of database server & $64 \%$ & $<70 \%$ \\
\hline & Maximum CPU utilization of web server & $57 \%$ & $<70 \%$ \\
\hline \multirow{2}{*}{ Memory usage } & Maximum memory usage of database server & $53 \%$ & $<70 \%$ \\
\hline & Maximum memory usage of web server & $37 \%$ & $<70 \%$ \\
\hline
\end{tabular}

TABLE 3: Correlation coefficient results of different indicators.

\begin{tabular}{lcccccc}
\hline & Solvency & Operating capacity & Profitability & Growth ability & Financial leverage & Nonfinancial indicators \\
\hline ST company & 0.82934 & 0.70318 & 0.67634 & 0.42125 & 0.24531 & 0.59219 \\
Non-ST company & 0.73241 & 0.93273 & 0.51341 & 0.54214 & 0.32149 & 0.63124 \\
\hline
\end{tabular}

TABle 4: Percentage distribution of career replanning and development of accountants.

\begin{tabular}{lccccc}
\hline & & Frequency & Percentage & Effective percentage & Cumulative percentage \\
\hline \multirow{2}{*}{ Financial AI } & Understand & 438 & 88.84 & 88.84 & 88.84 \\
& Do not understand & 55 & 11.16 & 11.16 & 100.00 \\
\hline \multirow{2}{*}{ Are you aware of postcrisis } & Yes & 348 & 70.59 & 70.59 & 70.59 \\
& No & 145 & 29.41 & 29.41 & 100.00 \\
\hline \multirow{2}{*}{ On career planning } & Existing planning & 175 & 35.50 & 35.50 & 35.50 \\
& Planning & 145 & 29.41 & 29.41 & 64.91 \\
& It is not planned & 108 & 21.91 & 21.91 & 86.82 \\
& I do not want to plan at all & 65 & 13.18 & 13.18 & 100.00 \\
\hline
\end{tabular}

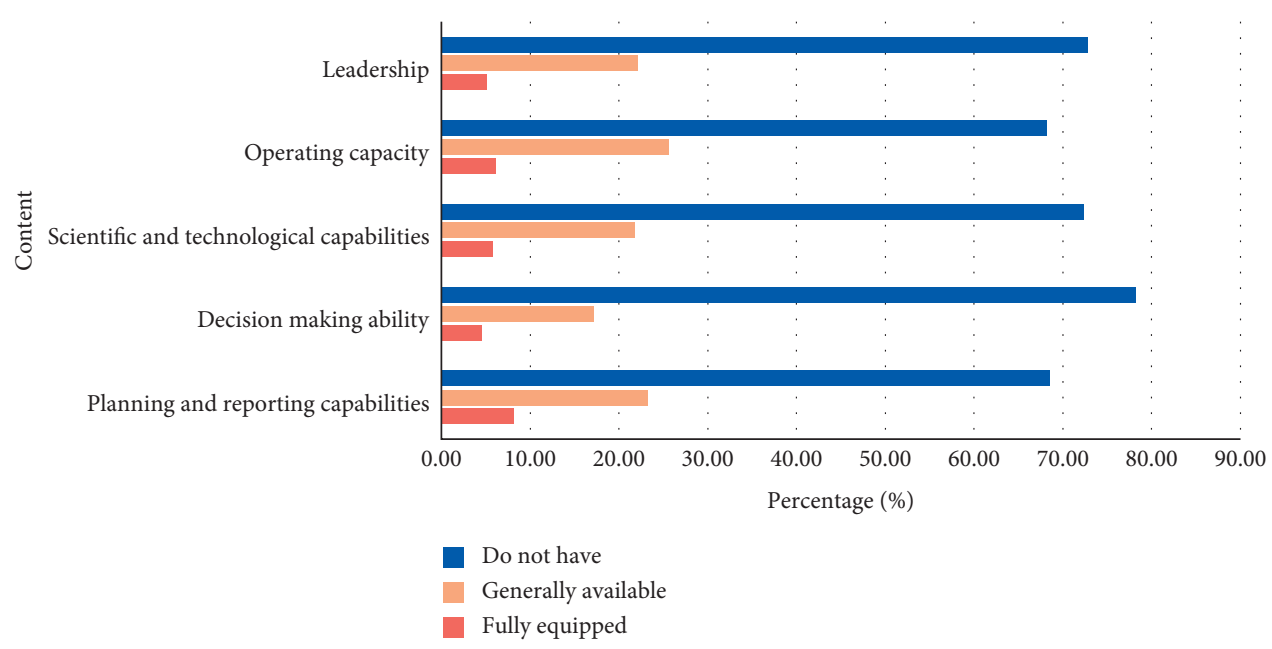

FIGURE 5: Statistics on the competence of management accountants.

The experimental results of the logistic model and RSlogistic model are compared as shown in Figure 6. The financial and accounting indicator system that has passed the significance test and the collinearity test will directly establish the logistic model, and its prediction accuracy rates for $\mathrm{T}-2, \mathrm{~T}-3$, and $\mathrm{T}-4$ are $90 \%, 71.25 \%$, and $57.5 \%$ in this order, respectively; and here on the basis of adding corporate governance indicators, the forecast accuracy has been significantly improved, followed by $91.25 \%, 72.5 \%$, and $60 \%$, respectively. That is, the logistic regression model is established directly using the index system that has passed the statistical test, and its prediction accuracy is lower than the early warning effect of the model built based on the RS reduction index system.

The descriptive statistics of factors affecting comprehensive profitability are shown in Table 5 . The correlation 


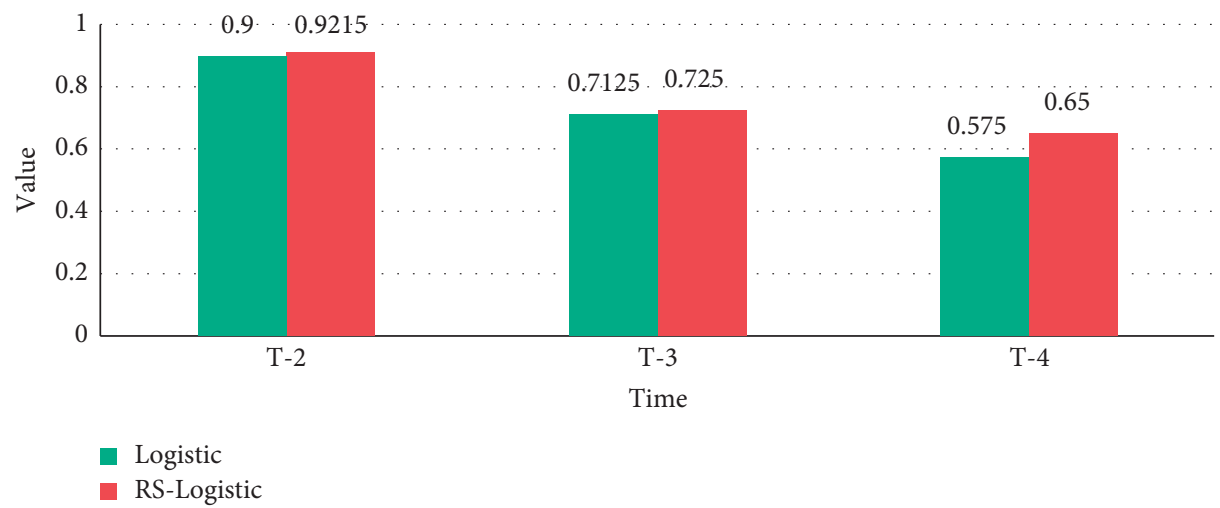

Figure 6: Comparison of experimental results between the logistic model and RS-logistic model.

TABle 5: Descriptive statistics of factors affecting comprehensive profitability.

\begin{tabular}{lccc}
\hline & Operating net profit margin & Turnover rate of total assets & Assets and liabilities \\
\hline Mean & 0.088731 & 0.342992 & 0.294594 \\
Median & 0.082263 & 0.246932 & 0.264624 \\
Max & 0.698856 & 2.381546 & 1.088260 \\
Min & -0.779646 & 0.015326 & 0.014037 \\
Std. dev & 0.132781 & 0.3482819 & 0.182120 \\
\hline
\end{tabular}

TABLE 6: Weights of first-level indicators.

\begin{tabular}{lcccc}
\hline & User dimension & Internal process dimension & Financial dimension & Dimensions of learning and development \\
\hline Numerical value & 0.3654 & 0.3005 & 0.1964 & 0.1378 \\
Proportion (\%) & 36 & 30 & 20 & 14 \\
\hline
\end{tabular}

coefficients of return on net assets and operating net interest rate, total asset turnover rate, and asset-liability ratio are $0.3275,0.0806$, and 0.0437 , respectively, and they are all significant under the condition of $5 \%$. The company with the worst product sales profitability of artificial intelligence concept stocks has a very serious negative value of operating net profit, reaching $-77.96 \%$; while the company with the best product sales profitability has an operating net profit of $69.89 \%$, which shows that the products of each company sales profitability is extremely uneven. It shows that the overall profitability of product sales of listed companies with artificial intelligence concept stocks has higher room for improvement.

The weights of the first-level indicators are shown in Table 6 . The user dimension accounts for about $36 \%$ of the weight, which is the most critical dimension to evaluate the effectiveness of the university's accounting sharing platform. As a second-category public welfare institution, colleges and universities provide high-quality services for the teaching and scientific research work of the teachers and students of the school, formulate policies for decision-makers and adopt reasonable suggestions, provide fast, effective, and comprehensive college accounting information and data analysis, and improve the satisfaction of all parties. This is where the responsibility and obligation of the accounting work of colleges and universities lie. The weight of the internal process dimension is about $30 \%$, second only to the weight of the user dimension. The data show that the optimization and reengineering of internal processes has become an important part of platform construction that cannot be ignored. The accounting dimension accounts for about $20 \%$ of the weight, which is one of the factors that cannot be ignored in the construction of the accounting sharing platform. Colleges and universities are nonprofit organizations, mainly based on financial funds provided by the state. With the advancement of the "double first-class" work, the state's financial investment in colleges and universities and the school's self-raised funds continue to increase. The learning and development dimension accounts for $14 \%$ of the weight, which does not mean that this dimension is not as important as the other three dimensions.

The influence relationship between each dimension is shown in Figure 7. The cause degree of each influencing factor is the difference between the degree of influence of each factor and the degree of being affected. The causal degree is mainly compared with 0 . If the causal degree of a certain factor is negative, then this factor is greatly influenced by other factors, and the influence on other factors is small, then the influencing factor is the result factor. If the causal degree of a certain factor is positive, then this factor is less affected by other factors and has a greater impact on other factors, then this factor is the causal factor. We must focus on the cause factors as the top priority of factor prevention and control. 


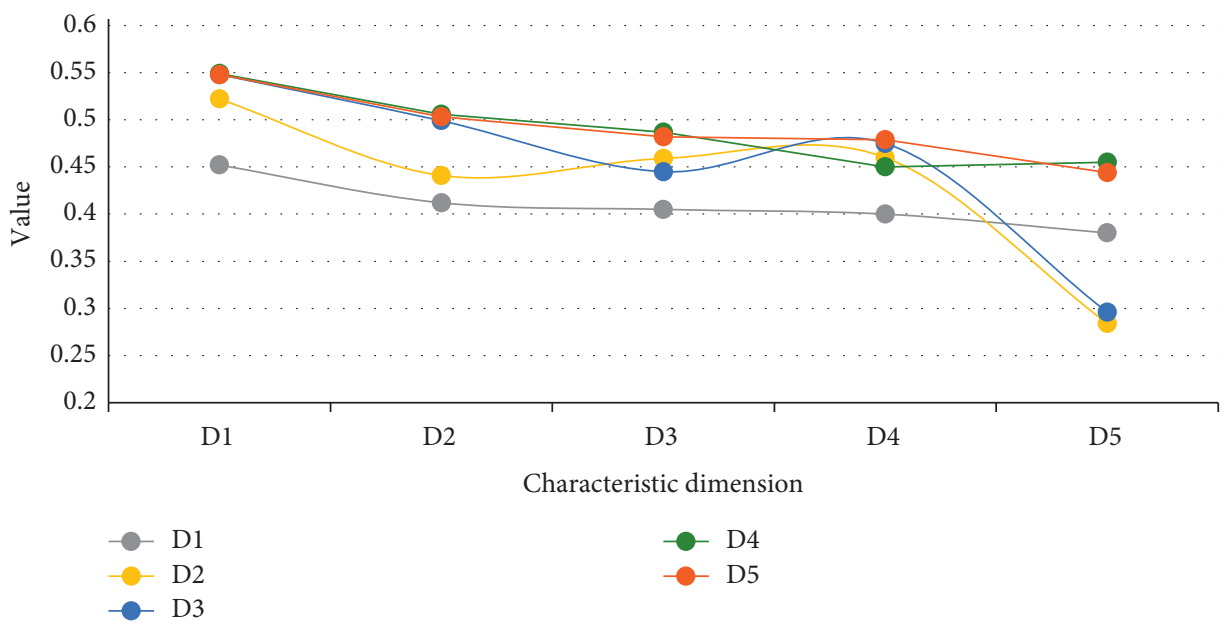

FIgURE 7: The influence relationship between the dimensions.

\section{Conclusions}

With the rapid development of network information technology and the gradual increase in the number of subsidiaries of enterprise groups, the model of shared service center for accounting has been adopted by more and more companies. It is an inevitable development trend that the model of shared financial and accounting service center is widely used in large enterprise groups. The innovative spirit of entrepreneurs determines the innovative atmosphere of the organization, which in turn affects the development and formation of financial management innovation; the capital capacity guarantees the infrastructure required for the implementation of corporate financial management innovation, the construction of financial management information networks, and the cultivation of excellent financial management teams. It is the basis for the smooth development of financial and accounting management innovation. Through the management of budget, financing, investment, and working capital by financial sharing center, the useful value information extracted can be timely and accurately provided to group companies, subsidiary companies, departments, and other users. At the same time, we should strengthen the quality of internal control of the group, prevent and control the operation risk of the financial sharing center through regular training of the personnel of the financial sharing center, and finally ensure the realization of value creation of the group.

\section{Data Availability}

No data were used to support this study.

\section{Conflicts of Interest}

Yaping Chen was born in Hancheng, Shaanxi, P.R. China, in 1984. She received the bachelor's degree from Xizang Minzu University, P.R. China. Now, she works in the College of Management, Shaanxi Institute of International Trade and Commerce. Her research interest includes financial management, business accounting, and regional economy.

\section{References}

[1] F. Wafula, "Effects of financial structure on financial performance of oil marketing companies in Kenya," International Journal of Economics and Finance, vol. 3, no. 4, pp. 763-778, 2020.

[2] Q. Gong, J. Y. Lin, and Y. Zhang, "Financial structure, industrial structure, and economic development: a new structural economics perspective," The Manchester School, vol. 87, no. 2, pp. 183-204, 2019.

[3] D. Chakrabarti, P. Sethi, and S. Bhattacharjee, "Directed credit, financial development and financial structure: theory and evidence," Applied Economics, vol. 51, no. 16-18, pp. 1711-1729, 2019.

[4] C. C. A. C. Ansca, K. A. Suyapto, K. A. Suyapto, T. Pranoto, and V. P. Gunawan, "The effect of capital structure and financial structure on firm performance (an empirical study of the financial crisis 2008 and 2009 in Indonesia)," Jurnal Akuntansi dan Keuangan Indonesia, vol. 16, no. 2, pp. 206223, 2019.

[5] G. Santos and S. P. O. Camilo, "Financial innovation solutions from blockchain technology in the perception of financial market agents," International Journal for Innovation Education and Research, vol. 7, no. 12, pp. 677-695, 2019.

[6] M. Perc, M. Ozer, and J. Hojnik, "Correction: social and juristic challenges of artificial intelligence," Palgrave Communications, vol. 5, no. 1, pp. 1-7, 2019.

[7] B. Dierynck and E. Labro, "Management accounting information properties and operations management," Foundations and Trends ${ }^{\circledR}$ in Technology Information and Operations Management, vol. 12, no. 1, pp. 1-114, 2018.

[8] N. M. Alsharari and M. Al-Shboul, "Evaluating qualitative research in management accounting using the criteria of "convincingness"," Pacific Accounting Review, vol. 31, no. 1, pp. 43-62, 2019.

[9] X. Hui, "Challenges and countermeasures of management accounting in the era of big data," World Scientific Research Journal, vol. 5, no. 10, pp. 115-121, 2019.

[10] S. R. Ndemewah, K. Menges, and M. R. W. Hiebl, "Management accounting research on farms: what is known and what needs knowing?" Journal of Accounting and Organizational Change, vol. 15, no. 1, pp. 58-86, 2019.

[11] S. Shahzadi, R. Khan, M. Toor, and A. U. Haq, "Impact of external and internal factors on management accounting 
practices: a study of Pakistan," Asian Journal of Accounting Research, vol. 3, no. 2, pp. 211-223, 2018.

[12] V. L. Mango, M. Sun, R. T. Wynn, and R. Ha, "Should we ignore, follow, or biopsy? Impact of artificial intelligence decision support on breast ultrasound lesion assessment," American Journal of Roentgenology, vol. 214, no. 6, pp. 1-8, 2020.

[13] N. R. M. B. A. Prem, M. K. M. S. Jaret, U. N. M. B. A. Benedict, and R. J. Williams, "Regarding " editorial commentary: artificial intelligence in sports medicine diagnosis needs to improve"," Arthroscopy: The Journal of Arthroscopic \& Related Surgery, vol. 37, no. 5, pp. 1365-1367, 2021.

[14] S. M. Ali, "“White crisis" and/as "existential risk," or the entangled apocalypticism of artificial intelligence," Zygon, vol. 54, no. 1, pp. 207-224, 2019.

[15] F. Cassalho, S. Beskow, C. R. Mello, M. M. Moura, L. F. Oliveira, and M. S. Aguiar, "Artificial intelligence for identifying hydrologically homogeneous regions: a state-ofthe-art regional flood frequency analysis," Hydrological Processes, vol. 33, no. 7, pp. 1101-1116, 2019.

[16] Z. Miao, "Investigation on human rights ethics in artificial intelligence researches with library literature analysis method," The Electronic Library, vol. 37, no. 5, pp. 914-926, 2019.

[17] L. F. d. C. Botega and J. C. Da Silva, “An artificial intelligence approach to support knowledge management on the selection of creativity and innovation techniques," Journal of Knowledge Management, vol. 24, no. 5, pp. 1107-1130, 2020.

[18] M. H. Yasir and A. Hussain, "Impact of financial structure on the financial stability: an empirical study in A sample of Iraqi companies," International Journal of Psychosocial Rehabilitation, vol. 24, no. 1, pp. 1997-2017, 2020.

[19] P. Thi Nga and T. Nguyen, "The impact of financial structure on profitability: empirical evidence from vietnam's construction sector," Asian Economic and Financial Review, vol. 10, no. 9, pp. 1028-1036, 2020.

[20] S. N. Maswadeh, "Financial structure effects on Jordanian banks tobin's Q," Review of Finance, vol. 19, no. 2021, pp. 35-41, 2021.

[21] O. U. Oro and A. H. Ekpo, "The value of the financial structure to economic performance in oil-producing countries," OPEC Energy Review, vol. 44, no. 1, pp. 43-58, 2020.

[22] D. Nisani, "Designing the financial structure of a preferred investment," International Journal of Business Research, vol. 19, no. 1, pp. 51-56, 2019.

[23] Z. Arslan and H. Zelk, "Effect of financial structure ratios on profitability: panel data analysis on manufacturing sector," Journal of Business Research-Turk, vol. 11, no. 1, pp. 504-516, 2019.

[24] Q.-J. Wang, G.-F. Feng, and C.-P. Chang, "Financial structure foundation of the urban- rural income gap in China: an investigation from the perspective of the double dual structure," Buletin Ekonomi Moneter dan Perbankan, vol. 22, no. 2, pp. 177-194, 2019.

[25] J. Hsieh, T.-C. Chen, and S.-C. Lin, "Financial structure, bank competition and income inequality," The North American Journal of Economics and Finance, vol. 48, pp. 450-466, 2019.

[26] X. Yin, "Government subsidies, financial structure and R \& D investment: evidence from Chinese SMEs," Journal of Service Science and Management, vol. 12, no. 2, pp. 186-199, 2019.

[27] M. Apan and M. Slamolu, "Determining the impact of financial characteristics on firm profitability: an empirical analysis on borsa istanbul energy firms," WSEAS Transactions on Business and Economics, vol. 15, no. 2018, pp. 547-559, 2019.

[28] F. Tael, E. B. Bayarcelik, and S. Apak, "Innovation decision of export companies and effect on firms financial performance," Financial and Credit Activity Problems of Theory and Practice, vol. 3, no. 30, pp. 176-185, 2019. 